\title{
Epidemiology of episodic adenolymphangitis: a longitudinal prospective surveillance among a rural community endemic for bancroftian filariasis in coastal Orissa, India Bontha V Babu*, Abhay N Nayak and Kalpataru Dhal
}

Address: Division of Epidemiology, Regional Medical Research Centre, Indian Council of Medical Research, Bhubaneswar - 751023 , India

Email: Bontha V Babu* - babubv@satyam.net.in; Abhay N Nayak - bontha99@hotmail.com; Kalpataru Dhal - bontha99@hotmail.com

* Corresponding author

Published: 19 May 2005

BMC Public Health 2005, 5:50 doi: 10.I I86/ I47|-2458-5-50

This article is available from: http://www.biomedcentral.com/I47/-2458/5/50

(c) 2005 Babu et al; licensee BioMed Central Ltd.

This is an Open Access article distributed under the terms of the Creative Commons Attribution License (http://creativecommons.org/licenses/by/2.0), which permits unrestricted use, distribution, and reproduction in any medium, provided the original work is properly cited.

\begin{abstract}
Background: The epidemiological knowledge on acute condition of lymphatic filariasis is essential to understand the burden and issues on management of the disease.

Methods: A one year long longitudinal prospective surveillance of acute adenolymphangitis (ADL) was carried out in rural population of Orissa, India.

Results: The annual incidence of ADL per 1000 individuals is 85.0 , and is slightly higher $(P>0.05)$ in male (92.0) than in female (77.6). A steady rise in the incidence of $A D L$ episodes along with the age is recorded. The distribution indicates that persons with chronic disease are more prone to ADL attacks. The average number of episodes per year is 1.57 (I.I5 SD) per affected person, and is gender dependent. Duration of the episode varies from I to II days with mean duration of 3.93 (I.94 SD) days. The chronic disease is the significant predictor for the duration of the episode. The data show that fever and swelling at inguinal regions are most common symptoms.

Conclusion: The incidence, frequency and duration of ADL episodes in this community are similar to that of other endemic areas. As the loss due to these ADL episodes is substantial, it should be considered while further estimating the burden due to lymphatic filariasis. The disability and loss caused by chronic forms of filariasis is higher, and the additional incapacity caused by the ADL episode, majority of which occur among chronic filariasis patients, further poses the burden on individuals and their families. Hence, morbidity management measures to prevent ADL episodes among endemic communities are to be implemented.
\end{abstract}

\section{Background}

Lymphatic filariasis (LF) is associated with a wide range of clinical signs, symptoms and sequelae, which are influenced by a variety of factors related to host and parasite. Acute episodes of adenolymphangitis (ADL) is one of the symptoms and this acute clinical manifestation is characterised by recurrent attacks of fever associated with inflammation of the lymph nodes and or lymph vessels
[1]. The importance of acute clinical manifestations, i.e. $\mathrm{ADL}$, in natural progression of the disease, particularly the development of chronic disease has been recognised by filarialogists [2-4]. Though the need of systematic epidemiological studies on acute LF or ADL is recognised, a few studies have been undertaken in different endemic areas [5-8]. The epidemiological information is useful to estimate the burden of the disease and to develop morbidity 
management strategies. The present paper, based on a longitudinal prospective fortnightly surveillance, reports some epidemiological aspects of ADL episodes among rural communities of Orissa, India, which is endemic for LF caused by Wuchereria bancrofti.

\section{Methods \\ Study area}

This one year longitudinal prospective surveillance for acute ADL episodes was carried out in two villages in Khurda district of Orissa, India. These two villages are close together by less than two kilometres and the geographical coordinates of these villages are $20^{\circ} 11^{\prime} \mathrm{N}$ and $85^{\circ} 40^{\prime} \mathrm{E}$, and $20^{\circ} 10^{\prime} \mathrm{N}$ and $85^{\circ} 38^{\prime} \mathrm{E}$. The study area is known for its endemicity for LF caused by Wuchereria bancrofti, which is transmitted by Culex quinquefasciatus. The microfilaria rate and density are $9.4 \%$ and $769 \mathrm{mf} / \mathrm{ml}$ respectively [9]. The total disease and chronic disease rates are $12.5 \%$ and $7 \%$ respectively [10]. The prevalence of infection based on circulating filarial antigenaemia is $39.9 \%$ [11]. One round of mass drug administration of diethylcarbamazine was given in the district in 1997 and recorded around 30\% of treatment compliance (BV Babu, unpublished data). However, no data specific to these two villages are available. The area is rural and its inhabitants are mostly small farmers and daily wage labourers.

\section{Data collection}

A population of 1329 ( 685 males and 644 females) of two villages were monitored for one year, during March 2000 - February 2001. Initially, the census of the villages was conducted for demographic information and identities of all individuals. The investigators visited all the households for every fortnight to detect individuals who were suffering or had suffered from an acute attack during that fortnight. In the present study, an acute ADL episode was defined as the presence of local signs and symptoms such as pain, tenderness, local swelling and warmth in the groin, with or without associated constitutional symptoms such as fever, nausea and vomiting [12]. The investigators, along with paramedical staff explained in the local language the symptoms of acute episodes, which are common in this endemic population. As there are no other diagnostic tools to identify ADL episodes, the present method of symptomatic diagnosis was used. This method of diagnosis through local terminologies was found to be highly specific (specificity $=0.980$ ) and sensitive (sensitivity $=0.978$ ) for diagnosing ADL [5]. For individuals identified as affected with acute attacks during last fortnight, the details including clinical symptoms, duration, etc. were recorded, by recall method and in case of ongoing episodes during visits, they were monitored. Majority of these cases are examined during the episode by physicians of local health institution. The available medical records/ prescriptions were used as adjunct. A few episodes are

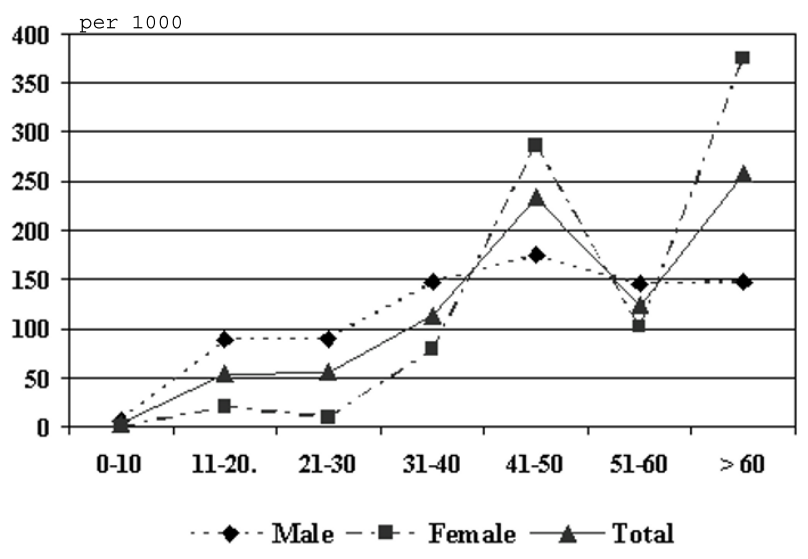

Figure I

Relation between annual incidence of ADL episodes and different age groups among male, female and total population.

clustered in members of the same household. The affected individuals were tested for microfilaraemia. A finger-prick thick blood film was prepared, using blood collected after 10 o'clock night, stained with Leishman's stain and entire film was examined for microfilariae.

\section{Data analysis}

The data were analysed through SPSS V.8 for Windows. The variation in incidence, frequency, number and duration of ADL episodes were assessed by employing the following statistical tests. Standardised normal Z-tests were performed to assess the variation in the incidence between different groups. Differences in number of episodes and duration of episodes were assessed by t-tests and analysis of variance (ANOVA). Multivariate ANOVA by regression was used to examine the effect of gender, age and pathological condition on the number and duration of episodes in affected individuals. The seasonal variation in the frequency of ADL episodes was assessed by $\chi^{2}$ test.

\section{Results}

\section{Incidence and distribution of acute episodes}

Number of fortnightly rounds completed during one year of study is 25 and 113 episodes were encountered among 72 patients in both villages. The annual incidence per 1000 population is 92.0 and 77.6 among men and women respectively, and the overall incidence is 85.0 per 1000 population. The difference between male and female is not significant $(P>0.05)$. However, the annual incidence is significantly high $(P<0.001)$ among individuals with chronic disease (957.0) than those without any chronic manifestations (19.4). The age-wise incidence of ADL episodes indicates a steady rise in the incidence of 
Table I: Association of gender, pathology group and age group with mean number of episodes and duration of episodes and details of multivariate ANOVA.

\begin{tabular}{|c|c|c|c|c|c|c|}
\hline \multirow{2}{*}{$\begin{array}{l}\text { Independent } \\
\text { Variable }\end{array}$} & \multirow{2}{*}{$\begin{array}{l}\text { Total number of } \\
\text { patients } \\
\text { in each category }\end{array}$} & \multirow{2}{*}{$\begin{array}{l}\text { Total number of } \\
\text { episodes } \\
\text { in each category }\end{array}$} & \multicolumn{2}{|c|}{ Mean number of episodes } & \multicolumn{2}{|c|}{ Mean duration (days) of episode } \\
\hline & & & Mean \pm SD & Coefficient $(P)^{\mathrm{a}}$ & Mean \pm SD & Coefficient $(P)^{\mathrm{b}}$ \\
\hline \multicolumn{7}{|l|}{ Gender } \\
\hline Male & 52 & 63 & $1.21 \pm 0.57$ & $1.169(0.000)$ & $3.95 \pm 2.05$ & $0.508(0.221)$ \\
\hline Female & 20 & 50 & $2.50 \pm 1.67$ & & $3.90 \pm 1.79$ & \\
\hline \multicolumn{7}{|l|}{ Pathology group } \\
\hline Hydrocele & 31 & 38 & $1.23 \pm 0.67$ & $0.276(0.07 I)$ & $4.56 \pm 2.34$ & $0.505(0.034)$ \\
\hline Lymphoedema & 19 & 47 & $2.47 \pm 1.71$ & & $3.74 \pm 1.76$ & \\
\hline Both & 3 & 4 & $1.33 \pm 0.58$ & & $3.67 \pm 1.15$ & \\
\hline None & 19 & 24 & $1.26 \pm 0.56$ & & $3.52 \pm 1.62$ & \\
\hline \multicolumn{7}{|l|}{ Age group } \\
\hline $7-20$ years & 10 & 16 & $1.60 \pm 1.08$ & $0.002(0.768)$ & $4.38 \pm 1.82$ & $0.023(0.0557)$ \\
\hline $21-40$ years & 30 & 40 & $1.33 \pm 0.84$ & & $4.24 \pm 2.41$ & \\
\hline $4 \mid-60$ years & 24 & 42 & $1.75 \pm 1.45$ & & $3.60 \pm 1.51$ & \\
\hline $61-75$ years & 8 & 15 & $1.88 \pm 1.25$ & & $3.64 \pm 1.80$ & \\
\hline Total & 72 & 113 & $1.57 \pm 1.15$ & & $3.93 \pm 1.94$ & \\
\hline
\end{tabular}

aFor number of episodes: $F=9.317(P<0.001)$, Adjusted $R^{2}=0.260$

bFor duration of episodes: $F=2.607(P<0.05)$, Adjusted $R^{2}=0.04$ I

episodes along with age among males and females, except in the age group of 51-60 years (Fig. 1).

A total of 72 (52 males and 20 females) individuals of the study population $(5.42 \%)$ were affected with acute ADLs. The age of the affected individuals varies from 7 years to 75 years with mean age of $36.23 \pm 16.46$ (SD) in case of male and $45.30 \pm 12.15(\mathrm{SD})$ in case of female, with a significant difference between two genders $(P<0.05)$. Among the total 72 patients suffered from acute episodes, overt chronic symptoms were found among 53 patients (73.61\%). Out of total 113 episodes, 47 (41.59\%) episodes are associated with lymphoedema, 38 (33.63\%) with hydrocele, 4 (3.54\%) with both lymphoedema and hydrocele and 24 episodes (21.24\%) in individuals without chronic manifestations (Table 1). The mean age of patients with chronic manifestations $(40.11 \pm 15.22 \mathrm{SD})$ is slightly higher than individuals without any chronic manifestations $(34.95 \pm 17.68 \mathrm{SD})$, but the difference is not significant $(P>0.05)$.

\section{Frequency and duration of acute episodes}

As 113 episodes were recorded among 72 patients, 20 $(27.8 \%)$ patients experienced more than one episode. Majority of patients $(52 ; 72.2 \%)$ experienced acute episode only once in the year. It is followed by $12.5 \%$ of patients with two episodes, $6.9 \%$ of patients with 3 episodes, $5.6 \%$ of patients with 4 episodes, and $1.4 \%$ of patients each with 5 and 7 episodes per year. Among the individuals with multiple episodes, majority (16 out of $20)$ are with chronic filarial symptoms $(P<0.001)$. The average number of episodes per year is 1.57 (1.15 SD) per affected individual. The multivariate ANOVA employed to assess the influence of age, gender and pathology on number of episodes per affected persons indicated that only gender is identified as significant predictor to the number of episodes per affected individual $(\mathrm{P}<0.001)$ (Table 1). Similar analysis is carried out to assess the effect of age among hydrocele patients, and age and gender among lymphoedema patients. These variables have no impact on frequency of episodes among hydrocele and lymphoedema patients $(P>0.05)$. There is significant variation in the frequency of ADL episodes with seasons of the year $(\mathrm{P}<0.001)$. The average numbers of episodes per month during summer (March to June), rainy season (July to October) and winter (November to February) are $11.00,10.75$ and 6.50 respectively.

Duration of the episode varies from 1 day to 11 days and the mean duration is 3.93 days ( $1.94 \mathrm{SD}$ ). In majority of cases, the episodes persisted for 3 days $(26.4 \%)$, followed by 4 days $(22.2 \%), 2$ days $(15.3 \%), 8$ days $(9.7 \%), 5$ days $(8.3 \%), 1$ day $(5.6 \%), 6$ days $(5.6 \%), 7$ days $(5.6 \%)$ and 11 days (1.4\%). When individuals' age, gender and pathology were considered simultaneously in multivariate ANOVA, the individuals' pathological condition emerged as a significant predictor to the mean duration of episode $(P<0.05)$ (Table 1$)$. When the hydrocele and 
lymphoedema patients are considered separately, age in hydrocele patients and, age and gender in lymphoedema patients have no significant impact on the duration of episode $(P>0.05)$.

\section{Clinical symptoms associated with ADL episodes}

Distribution of various clinical symptoms among these acute cases is presented in Table 2. Occurrence of fever $(77.87 \%)$ and swelling of inguinal regions (63.72\%) are most common symptoms of acute cases. In the local language, swelling of lymphatic nodes is known as Bagi or Pichhuli, and is commonly perceived as the initial symptom of LF among the study population. Pain and tenderness in different body parts are seen in majority of cases. Presence of local swelling, anorexia, nausea and vomiting are associated with ADL among majority of cases. It is attempted to examine the differences in clinical presentation across gender and pathological groups. There are no significant variations in occurrence of these symptoms except in occurrence of pain and tenderness. Pain and tenderness in genitals is common in hydrocele patients, and hence more frequent in male patients. In lymphoedema patients, pain and tenderness are noticed in lower limbs. No association was found between occurrence of these symptoms and age groups. The microfilarae data indicated that only 8 , out of 72 acute patients (11.11\%) are microfilaraemic.

Table 2: Distribution of associated symptoms among the ADL cases.

\begin{tabular}{lrr}
\hline Symptom & $\begin{array}{c}\text { Prevalence among } \\
\text { episodes }\end{array}$ & Percentage \\
\hline Pain in & 12 & \\
Upper arms & 10.62 \\
Legs & 23 & 73.45 \\
Genitals & 29 & 20.00 \\
Breasts & 1 & 0.88 \\
Tenderness in & & \\
Upper arms & 10 & 8.85 \\
Legs & 13 & 11.50 \\
Genitals & 24 & 21.24 \\
Lymphangitis in & & \\
Left inguinal region & 34 & 30.09 \\
Right inguinal region & 38 & 33.63 \\
$\quad$ Left papillary & 3 & 2.65 \\
Right papillary & 3 & 2.65 \\
Swelling & 92 & 81.42 \\
Fever & & \\
High & 61 & 53.98 \\
$\quad$ Low & 27 & 23.89 \\
Anorexia & 72 & 63.72 \\
Nausea & 61 & 53.98 \\
Vomiting & 32 & 28.32 \\
Microfilaraemiae & 13 & $11.50^{\mathrm{a}}$ \\
& & \\
& &
\end{tabular}

apercentage is to total number of patients

\section{Discussion}

To develop strategies for relieving and preventing the suffering of filarial patients, it is essential to understand the epidemiology of various forms of morbidity. The information on acute form of LF, particularly on ADL is sporadic from a few endemic regions. The present longitudinal prospective surveillance showed the annual incidence of 85.03 of ADL episodes per 1000 population in this rural Eastern Indian community. Similarly, a South Indian rural community, which is endemic for bancroftian filariasis recorded the annual incidence of 96.3 per 1000 population [6]. The incidence rates are available from a few other endemic countries such as Ghana (96 per 1000 population) [5] and Tanzania (33 per 1000 population) [8]. The proportion of people affected with ADL episodes in the present study $(5.4 \%)$ is similar to that reported from another bancroftian filarial endemic community from South India (5.3\%) [6]. The age wise distribution indicates that male recorded higher incidence in all age groups except in the age groups of 41-50 years and above 60 years of age. This age-wise incidence follows the pattern with the prevalence of microfilaraemia and chronic disease [13]. The variation could be due to differences in prevalence of chronic disease and differential susceptibility to ADL episodes for individuals with lymphoedema and hydrocele. In the present population, men recorded higher prevalence of chronic filarial disease than women [10]. The mean age of affected individuals is varying between male and female. The lower mean age of male patients may be due to occurrence of hydrocele even at lower age. In the present study population, majority of affected individuals has only one episode per year and only $27.8 \%$ of affected individuals have experience more than once. The data showed that these multiple episodes are more common in patients with chronic disease. The mean number of episodes per year is significantly higher among lymphoedema patients than even hydrocele patients. A study from South India reported a direct relationship between the number of acute attacks and the grade of lymphoedema [14]. It is also known that the frequency of these attacks is generally higher in bancroftian filariasis as compared to brugian filariasis [14,15]. Regarding the seasonal variation in the frequency of ADL episodes, it is lower in winter than is summer and rainy season. Some of the earlier studies reported higher frequency in rainy season $[16,17]$. In Tanzania, the higher incidence of ADL episodes during rainy season is related to increased transmission by infective mosquito bites [8]. It is consistent with the hypothesis that ADL episodes may be associated with allergic responses to massive parasite antigen release $[18,19]$. There is uniformity in the associated symptoms of ADL episodes amongst various endemic communities, though the etiology of the ADL is not clear. The majority of the ADL patients in this study are amicrofilaraemic, and this finding is in conformity 
with earlier observations $[5,19,20]$. The limitation of this study is that an insensitive method of microfilaria detection was used, i.e., finger prick method as opposed to Nucleopore filtration method.

The incidence and duration of the ADL episode has greater economic implication on individuals, their families and community. There will be substantial loss of work during these episodes and subsequent economic loss [2123]. In the present study population, on average each episode persists for 4 days, which is similar to the other endemic areas $[6,8,16,24,25]$. The magnitude of loss due to ADL episodes is substantial and it will be constituted as a major proportion to the total burden of LF. While estimating the global burden of LF, only the chronic forms of disease were considered [26], perhaps due to lack of data at that time. As the data on incidence and duration of ADL episodes are available at least from some endemic areas, they should be considered during further estimation of disease burden due to LF. In the present study community, it is reported that the chronic condition is posing considering economic burden due to loss of work and treatment costs [27]. It is well known that the disability and economic loss caused by chronic filariasis is life long and much higher. And additional incapacity caused by the ADL episodes, majority of which occur in these chronic filarial patients, further poses the burden on the individuals and their families. It is clear that there are two types of ADL episodes, ADL secondary to bacterial or fungal infections and ADL caused directly by the parasite infection itself [1]. For the episodes among chronic lymphoedema cases, secondary bacterial infection may be plausible explanation [28-30]. It is also evident from recent findings that simple foot hygiene and prevention of secondary bacterial infection lower the incidence of ADL episodes [28,31-33]. Shenoy et al. [34] demonstrated that well designed programme of foot care significantly decreases the frequency of ADL episodes. In this programme, meticulous hygiene including use of foot wear, regular washing of affected limbs, etc. to prevent injuries and infections needs to be incorporated. Thus, it is essential to develop and promote simple, cost-effective and user-friendly measures to minimise the burden of acute disease of LF.

\section{Competing interests}

The author(s) declare that they have no competing interests.

\section{Authors' contributions}

BVB conceived and designed the study; performed analysis and interpretation of data; and drafted the paper. ANN collected and computerised the data; KD collected the data. All authors read and approved the final manuscript.

\section{Acknowledgements}

This study has been carried out with intra-mural funding of Regional Medical Research Centre (Indian Council of Medical Research), Bhubaneswar, India. Authors are grateful to Dr. S.K. Kar, Director, Regional Medical Research Centre, for his encouragement for research and publications. Authors are also grateful to Prof. J.W. Kazura, Dr. K.D. Ramaiah and Dr. P.K. Das for their comments as reviewers for refinement of the manuscript.

\section{References}

I. Kumaraswami V: The clinical manifestations of lymphatic filariasis. In Lymphatic Filariasis Edited by: Nutman TB. London: Imperial College Press; 2000:103-126.

2. Turner LH: Studies on filariasis in Malaya: the clinical features of filariasis due to Wuchereria malayi. Trans Roy Soc Trop Med Hyg 1959, 53:154-169.

3. Edeson JFB, Wilson $\mathrm{T}$ : The epidemiology of filariasis due to Wuchereria bancrofti and Brugia malayi. Ann Rev Entomol I964, 9:245-268.

4. Raghavan NGS: Clinical manifestations and associated epidemiological factors of filariasis. J Commun Dis 1969, I:75- I02.

5. Gyapong JO, Gyapong M, Adjei S: The Epidemiology of acute adenolymphangitis due to lymphatic Filariasis in Northern Ghana. Am J Trop Med Hyg 1996, 54:591-595.

6. Ramaiah KD, Ramu K, Vijay Kumar KN, Guyatt H: Epidemiology of acute filarial episodes caused by Wuchereria bancrofti infection in two rural villages in Tamil Nadu, South India. Trans Roy Soc Trop Med Hyg 1996, 90:639-643.

7. Alexander ND, Perry RT, Dimber ZB, Hyun PJ, Alpers MP, Kazura JW: Acute disease episodes in a Wuchereria bancroftiendemic area of Papua New Guinea. Am J Trop Med Hyg 1999, 61:319-324.

8. Gasarasi DB, Premji ZG, Mujinja PGM, Mpembeni R: Acute adenolymphangitis due to bancroftian filariasis in Rufiji district, South East Tanzania. Acta Trop 2000, 75: 19-28.

9. Dash AP, Mohapatra N, Hazra RK, Acharya AS: Transmission dynamics of filariasis in Khurda district of Orissa, India. Southeast Asian J Trop Med Pub Health 1998, 29: I37-140.

10. Babu BV, Acharya AS, Mallick G, Jangid PK, Nayak AN, Satyanarayana $\mathrm{K}$ : Lymphatic filariasis in Khurda district of Orissa, India: an epidemiological study. Southeast Asian J Trop Med Pub Health 200I, 32:707-710.

II. Sahoo PK, Geddam JJB, Satapathy AK, Mohanty MC, Ravindran B: Bancroftian filariasis: prevalence of antigenaemia and endemic normals in Orissa, India. Trans Roy Soc Trop Med Hyg 2000, 94:5I5-517.

12. WHO: Lymphatic Filariasis: Disease and its Control. Fifth Report of the WHO Expert Committee on Filariasis. In Technical report series No. 82I Geneva: World Health Organization; 1992.

13. Brabin L: Sex differentials in susceptibility to lymphatic filariasis and implications for maternal/child immunity. Epidemiol Inf 1990, 105:335-353.

14. Pani SP, Yuvaraj J, Vanamail P, Dhanda V, Michael E, Grenfell BT, Bundy DAP: Episodic adenolymphangitis and lymphoedema in patients with bancroftian filariasis. Trans Roy Soc Trop Med Hyg 1995, 89:72-74.

15. Pani SP, Krishnamoorthy K, Rao AS, Prathiba J: Clinical manifestation in malayan filariasis with special reference to lymphoedema grading. Ind J Med Res 1990, 81:200-207.

16. Rao CK, Chandrasekharan A, Cherian G: Frequency and duration of acute filarial attacks in persons in Brugia malayi endemic community. Ind J Med Res 1982, 75:8I3-8I5.

17. Ravindranathan TC, Sethumadhaya KVP, Roychoudhary SP, Babu CS, Kanoujia KH, Narasimham MVVL, Rao CK: Seasonal variation in microfilaraemia (bancrofti) density and filarial disease. J Commun Dis 1980, I 2:73-77.

18. Kar SK, Mania J, Kar PK: Humoral immune response during filarial fever in bancroftian filariasis. Trans Roy Soc Trop Med Hyg 1993, 87:230-233.

19. Addiss DG, Eberhard ML, Lammie JP: Filarial adenolymphangitis without filarial infection. Lancet 1994, 343:597.

20. Michael E, Grenfell BT, Bundy DAP: The association between microfilaraemia and disease in lymphatic filariasis. Proc Roy Soc London B 1994, 256:33-40. 
21. Sabesan S, Krishnamoorthy K, Pani SP, Panicker KN: Man-days lost due to repeated acute attacks of lymphatic filariasis. Trends in Life Sciences (India) 1992, 7:5-7.

22. Ramaiah KD, Ramu K, Das PK, Kumar KN, Pani SP: Direct and indirect costs of the acute form of lymphatic filariasis to households in rural areas of Tamil Nadu, South India. Trop Med Int Health 1998, 3:108-115.

23. Babu BV, Nayak AN: Treatment costs and work time loss due to episodic adenolymphangitis in lymphatic filariasis patients in rural communities of Orissa, India. Trop Med Int Health 2003 , 8:1102-1109.

24. Kimura E, Penaia L, Spears GFS: Epidemiology of sub-periodic bancroftian filariasis in Samoa 8 years after control by mass treatment with diethylcarbamazine. Bull World Health Organ 1985, 63:869-878

25. Partono F: The spectrum of disease in lymphatic filariasis. Filariasis, Ciba Foundation Symposium No. 127 1987: I5-3I.

26. Michael E, Bundy DAP, Ottesen E, Ramachandran CP: Global bur den of disease: prevalence of disease in lymphatic filariasis. Parasitology 1996, I I 2:409-428.

27. Babu BV, Nayak AN, Dhal K, Acharya AS, Jangid PK, Mallick G: The economic loss due to treatment costs and work loss to individuals with chronic lymphatic filariasis in rural communities of Orissa, India. Acta Trop 2002, 82:31-38.

28. Shenoy RK, Sandhya K, Suma TK, Kumaraswami V: A preliminary study of filarial related acute adenolymphangitis with specia reference to precipitating factors and treatment modalities. Southeast Asian J Trop Med Pub Health 1995, 26:301-305.

29. Olszewski WL, Jamal S: Skin bacterial factor in progression of filarial lymphoedema. Lymphology 1994, 27: | 48-| 49.

30. Olszewski WL, Jamalm S, Manokaran G, Pani S, Kumaraswami V, Kubicka U, Lukomska B, Dworczynski A, Swoboda E, Meisel-Mikolajczyk F: Bacteriologic studies of skin, tissue fluid, lymph and lymph nodes in patients with filarial lymphodema. Am J Trop Med Hyg 1997, 57:7-I5.

31. Shenoy RK, Suma TK, Rajan K, Kumaraswami V: Prevention of acute adenolymphangitis in brugian filariasis: comparison of the efficacy of invermectin and diethylcarbamazine, each combined with local treatment of the affected limb. Ann Trop Med Parasitol 1998, 92:587-594.

32. Burri H, Loutan L, Kumaraswami V, Vijayasekaran V: Skin changes in chronic lymphatic filariasis. Trans Roy Soc Trop Med Hyg 1996, 90:67I-674.

33. Dreyer G, Medeiros Z, Netto MJ, Leal NC, de Castro LG, Piessens WF: Acute attacks in the extremities of persons living in an area endemic for bancroftian filariasis: differentiation of two syndromes. Trans Roy Soc Trop Med Hyg 1999, 93:4I3-4I7.

34. Shenoy RK, Kumarswami V, Suma TK, Rajan K, Radhakuttyamma G: A double blind placebo controlled study of the efficacy of oral pencillin, diethyl-carbamazine or local treatment of the affected limb in preventing acute adenolymphangitis in lymphodema caused by brugian filariasis. Ann Trop Med Parasitol 1999, 93:367-377.

\section{Pre-publication history}

The pre-publication history for this paper can be accessed here:

http://www.biomedcentral.com/1471-2458/5/50/prepub

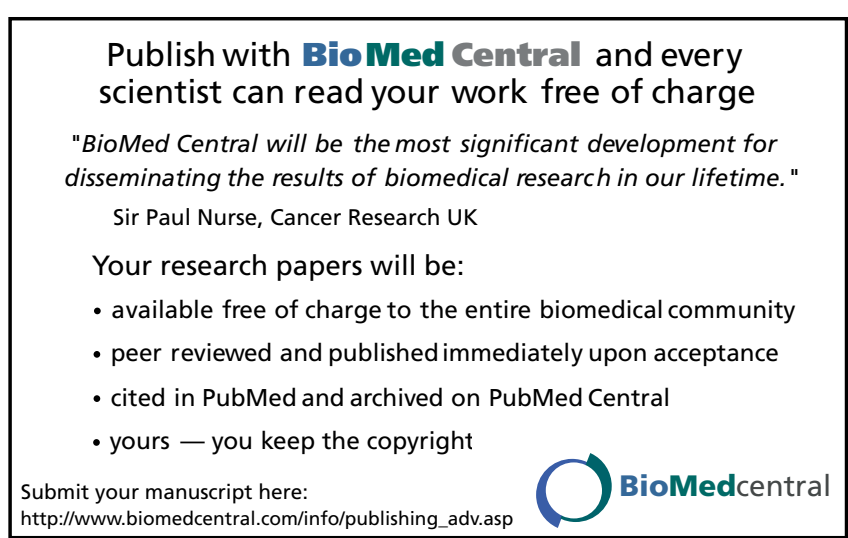

